\title{
Perception and Production of Five English Front Vowels by College Students
}

\author{
Ching-Ying $\operatorname{Lin}^{1}$ \\ ${ }^{1}$ Faculty of Department of Applied English, National Pingtung University, Taiwan \\ Correspondence: Ching-Ying Lin, Faculty of Department of Applied English, National Pingtung University, \\ Taiwan. E-mail: chingyinglin6@gmail.com
}

Received: June 20, 2014 Accepted: July 21, 2014 Online Published: August 14, 2014

doi:10.5539/elt.v7n9p14 URL: http://dx.doi.org/10.5539/elt.v7n9p14

\begin{abstract}
This study was to explore whether college students could perceive and produce five English front vowels well or not. It also examined the relationship between English speaking and listening. To be more specific, the study attempted to probe which vowels that learners could be confused easily in speaking and listening. The results revealed that participants perceived the best in /i///I/ pair and /e/-/æ/ pair but the worst in /e/-/E/ pair, /E/-/æ/ pair and among $/ \mathrm{e} /-/ \varepsilon /-/ \mathfrak{x} /$ pair. They produced the best in the vowels of $/ \mathrm{I} /$ and $/ \varepsilon /$ but the worst in the vowels of $/ \mathrm{i} /$, /e/ and /æ/. Moreover, there was a strong and positive correlation between production and perception of English vowels by college students.
\end{abstract}

Keywords: English perception, English production, English front vowels, relationship between English perception and production, college students

\section{Introduction}

Having good pronunciation can make people express message clearly in communication. Good pronunciation also allows people understand briefly what the speaker says. In Taiwan, students learn English as a foreign language but they don't have many opportunities to practice speaking and listening. Due to the fact, as a non-native speaker, he or she may feel upset or may be afraid of making mistakes when they communicate with native speakers due to they don't have enough training in pronunciation. Although English teachers or foreign language teachers know how important the pronunciation is, little attention has been paid to the students' learning process of second or foreign language learning. Moreover, school teachers can't correct each student's pronunciation mistakes because there are too many students in one class.

Except for insufficient practice, learners may be interfered with their L1 when they are learning target language pronunciation, and it is a common situation in Taiwan (Cheng, 2004). In addition, the contents of most current English textbooks omit the pronunciation teaching so that non-native learners can't learn how to pronounce English correctly (Lin, 1994). EFL teachers should not only be aware of what kind of difficulties the students have but also pay attention to choose the appropriate pronunciation materials so that they can help their students improve the proficiency in pronouncing.

Lin (1994) argued that Mandarin Chinese learners can't perform well in English speaking due to the fact of the language between English and Chinese exist in different linguistic systems. The fact is that EFL learners may be interfered with their L1 when they are learning second or foreign language. It is a vital issue to examine what English learning difficulties students have in producing and perceiving in order to improve their accuracy. However, there were limited studies to explore Taiwanese EFL adult learners' production of English vowels (Cheng, 2004).

Wang (1997) stated that few studies have explored Mandarin speakers' learning problem in producing English vowel, and limited researches have been examined the parallel test about English production and perception so that it is difficult to explore the correlation between English perception and production. Moreover, Taiwanese EFL learners have learning difficulties in perceiving and producing the vowels /i/, /I/, /e/, / $\varepsilon /$ and $/ \mathfrak{a} /(\mathrm{Ho}, 2010)$. Cheng (2004) indicated that it is a difficult task to produce the vowel /æ/ for Taiwanese native speakers. They are also confused the pair vowels of /i/ and /I/. On the other hand, Lin (2013) stated that L2 learners perform worse in $/ \varepsilon /-$ ær/ pair than /i/-/I/ pair. 
It is necessary to find out what kind of perception and production difficulties EFL learners have for helping them improve their English speaking and listening (Lin, 2013). This study was to explore whether college students could perceive and produce five English front vowels well or not. It also examined the relationship between speaking and listening. To be more specific, the study attempted to probe which vowels learners could be confused easily in speaking and listening. Three research questions are addressed as follows:

1) Among the five front vowels /i/, /I/, /e/, / / /, /æ/, which front vowels do college students perform the best or worst in listening?

2) Among the five front vowels $/ \mathrm{i} /, / \mathrm{I} /, / \mathrm{e} /, / \varepsilon /, / æ /$, which front vowels do college students perform the best or worst in speaking?

3) Is there a correlation between English perception and production of these English vowels?

\section{Literature Review}

This part reveals the literature related with learners' perception and production of English front vowels. The correlation of English front vowels between perception and production is presented. A summary of the literature is provided to conclude this part.

In order to help students improve their English production and perception, it is necessary to probe what kind of problems students have in their English pronunciation. Lin (2013) recruited 20 Grade $6^{\text {th }}$ students to explore which minimal pairs of vowels $(/ \mathrm{i} / / / \mathrm{I} /, / \varepsilon /-/ \mathfrak{x} /)$ students perform well or worst and the correlation between production and perception of $/ \mathrm{i} /, / \mathrm{I} /, / \varepsilon /, / \mathfrak{l} /$. There were two kinds of instruments, perception test and production test, employed in this study. Paired sample t-tests and correlation analyses were used to analyze the data. The results indicated that students perceived and produced the vowels of $/ \mathrm{i} /-\mathrm{I} /$ pair better than $/ \varepsilon /-/ \mathfrak{z} /$ pair. However, students had better performance in perceiving and producing /i/ better than $/ \mathrm{I} /$ and they produced $/ \varepsilon /$ better than

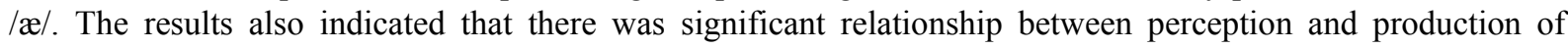
English vowels. Lin and Chen (2005) also stated that Mandarin speakers performed pretty well in perception of /i/-/I/ pair.

In Ho's study (2010), there were 30 students employed in the study. The purpose was to examine what problems in perceiving English front vowels $(/ \mathrm{i} /, / \mathrm{I} /, / \mathrm{e} /, / \varepsilon /$ and $/ \mathfrak{m} /)$ the students have. The results indicated that students perceived /i/ and /æ/ better than other vowels. However, students didn't have good performance in perceiving /e/. This might be that both Mandarin and Minnan have a sound which is close to vowel /i/. In addition, the vowel /æ/ doesn't get closer to Mandarin; it might be that the /æ/ sound has an outstanding acoustic feature that students can recognize easily. In addition, students can't make distinguish easily between /i/-/I/ pair. They also have confusion among /e/, / $\varepsilon /$ and /æ/ in perceiving.

Cheng's study (2004) was to probe Taiwanese adult speakers' difficulties in producing ten English vowels

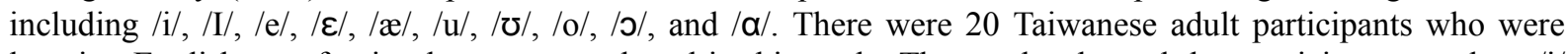
learning English as a foreign language employed in this study. The results showed that participants produce /i/ and /e/ worse than $/ \mathrm{I} /$ and $/ \varepsilon /$.

However, Lin (1994) stated that Chinese male speakers performed well in producing /e/ and /æ/, and Chinese female speakers produced better in $/ \mathrm{i} /, / \mathrm{e} /$ and $/ \mathfrak{x} /$. The results also indicated that Chinese male speakers have difficulties in distinguishing between /i/ and /I/. The female speakers didn't pronounce/I/ well, either. In addition, both Chinese male and female speakers have problems in producing $/ \varepsilon /$.

In Chen, Chang, Yang, and Chou's (2006) study, there were 19 male and 20 female Taiwanese university students employed in this research. All of the subjects are native Chinese-speaker and major in foreign language. Most of them have at least seven years in learning English. The results revealed that vowel /æ/ show high percentages of total errors in production. Over $69 \%$ students produced $/ \mathfrak{x} /$ as vowel $/ \mathrm{e} /$, and $16 \%$ students produced as $/ \varepsilon /$. Moreover, $97 \%$ students produced / $\varepsilon /$ as /e/. It displayed that Taiwanese students have much more errors in lax vowels.

Tseng (2011) was to examine 102 Taiwanese senior high school students' perception and production of English front vowels $/ \mathrm{e} /, / \varepsilon /$ and $/ \mathfrak{x} /$. The instruments included perception test and production test. The results showed

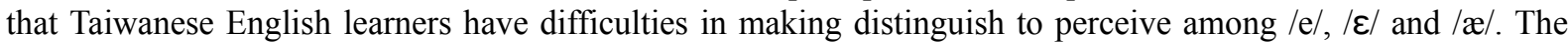
vowel $/ \mathcal{E} /$ is the hardest and the vowel $/ \mathfrak{x} /$ is the easiest to perceive. In addition, students have problems in producing /e/, the vowel /æ/ is easier for them to pronounce.

Mokari, Famian, and Ghafoori (2013) recruited 30 EFL learners to examine the correlation between perception and production of English vowels. The results showed that learners who can produce English vowels well could 
also have good performance in perceiving English vowels. However, Cho and Jeong (2013) argued that there no significant relationship between perception and production of English vowels by Korean EFL learners. The results also probed that learners tend to be poorly discriminated in pronouncing and perceiving between /i//I/ pair and /E/-/æa/ pair. However, Broboza (2007) indicated that /i///I/ pair is easy to recognize and produce but the $/ \varepsilon /-/ \mathfrak{\&} /$ pair is confused in production as well.

There were 81 junior English majors participated in Zhou, Chen, and Dai's study (2011). The purpose was to explore Mandarin native speakers' English perception. The results indicated that students had good performance in perceiving $/ \mathrm{i} /, / \mathrm{I} /, / \mathrm{u} /$ and $/ \mathbf{\alpha} /$ while they perceived worst in $/ \mathfrak{a} /$ and $/ \mathrm{N} /$.

In sum, previous studies exploring the production of English front vowels by Taiwanese adult learners have been scarce. Moreover, the correlation between perception and production of English front vowels has produced conflicting results. Therefore, this study intended to probe the college students' performance of English front vowels in perceiving and producing, and the correlation between English production and perception.

\section{Methodology}

\subsection{Subjects}

A total of 17 college students voluntarily participated in the present study. There were four English majors including three sophomores and one junior. 11 non-English majors were freshmen. In addition, there were one non-English major junior and one non-English major senior. All of the four English majors had pronunciation class in their first year of the college. In the other words, the four English majors had been trained in perceiving and producing English vowels before. Besides, there was a non-English major freshman who studied in English major in the senior high school. She had also been trained before she went to college school. The demographic data was shown in Table 1.

Table 1. Demographic data of the survey participants

\begin{tabular}{|c|c|c|c|}
\hline Level Major & English Major & Non-English Major & Total \\
\hline Freshman & & 11 & 11 \\
\hline Sophomore & 3 & & 3 \\
\hline Junior & 1 & 1 & 1 \\
\hline Senior & & 1 & 1 \\
\hline Total & 4 & 13 & 17 \\
\hline
\end{tabular}

\subsection{Instruments}

There were two instruments in this study. One was the speaking task and the other was the listening task. Both of the tasks contained five English front vowels $/ \mathrm{i} /, / \mathrm{I} /, / \mathrm{e} /, / \mathcal{E} /$ and $/ \mathfrak{x} /$. In the speaking task, there were phonetic symbols along with words to help participants produce; their production would be recorded by mobile phone. The acoustic data would be translated in electronic document. The listening records have been made by the researcher. It only broadcast one time and the participants required to choose the correct response they heard.

\subsection{Procedures}

It cost 15 minutes in each test. Before giving an examination about production and perception of English front vowels, all of the subjects were told that their speaking and listening tests won't be affected their scores at school in order to reduce their anxiety. In addition, to avoid participants noticing the accurate pronunciation, the participants have been required to do the perception task first.

\subsection{Data Analyses}

The data were analyzed by the SPSS (Statistics Package for Social Science, version 12.0). First, descriptive statistics such as frequencies and percentage were computed to display the subjects' perception and production of English front vowels. Second, Pearson product-moment correlations were conducted to determine the relationships between perception and production of English front vowels.

\section{Results}

The statistical results are addressed in accordance with the sequence of the research questions which involve: a) production of English front vowels, b) perception of English front vowels, c) which front vowels confused 
students easily in perceiving, and d) relationship between perception and production of English front vowels.

Research question 1: Among the five front vowels /i/, /I/, /e/, / $/$ /, /a/, which front vowels do college students perform the best or worst in listening?

Table 2. Frequencies of English front vowels perception

\begin{tabular}{lllllllllll}
\hline Vowels & $/ \mathrm{i} /$ & & $/ \mathrm{I} /$ & & $/ \mathrm{e} /$ & & $/ \varepsilon /$ & \multicolumn{3}{c}{$/$ / } \\
\hline$f$ & $\mathrm{~N}$ & $\%$ & $\mathrm{~N}$ & $\%$ & $\mathrm{~N}$ & $\%$ & $\mathrm{~N}$ & $\%$ & $\mathrm{~N}$ & $\%$ \\
\hline 1 & & & 1 & 5.9 & 2 & 11.8 & 3 & 17.6 & & \\
2 & 1 & 5.9 & & & 2 & 11.8 & 3 & 17.6 & 2 & 11.8 \\
3 & 3 & 17.6 & 1 & 5.9 & 3 & 17.6 & 8 & 47.1 & 6 & 35.3 \\
4 & 4 & 235. & 6 & 35.3 & 2 & 11.8 & 1 & 5.9 & 6 & 35.3 \\
5 & 9 & 52.9 & 9 & 52.9 & 8 & 47.1 & 2 & 11.8 & 3 & 17.6 \\
Total & 17 & 100 & 17 & 100 & 17 & 100 & 17 & 100 & 17 & 100 \\
\hline
\end{tabular}

As shown in Table 2, learners have good performance in perceiving $/ \mathrm{i} /(\mathrm{N}=13,4 \leqq f=5)$ and $/ \mathrm{I} /(\mathrm{N}=14,4 \leqq f$ $=5)$, However, they perceived worst in $/ \varepsilon /(\mathrm{N}=6,1 \leqq f=2)$. In the minimal pair of $/ \mathrm{i} /$ and $/ \mathrm{I} /$, most students could recognize the vowels easily, but a variety of students would get confused among vowels /e/, / $/ \varepsilon /$ and $/ æ /$,

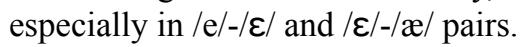

Table 3. Minimal Paris of vowels /i/-/I/ $(\mathrm{N}=17)$

\begin{tabular}{lll}
\hline Words & Vowels & /i/ \\
\hline least /list/ & 15 & 2 \\
fit $/$ fit/ & 3 & 14 \\
leek $/$ lik/ & 17 & 0 \\
sea $/ \mathrm{si} /$ & 15 & 2 \\
nit $/ \mathrm{nIt} /$ & 1 & 16 \\
\hline
\end{tabular}

In Table 3, the results of students chosen had briefly showed that most of the students perceived well between /i/-/I/ pair. When broadcasted the word "least", only two participants chose the word "list". Only three participants picked up the word "feet" when they heard "fit". None of them chose "lid" when the recording played the word "leek". Two of participants chose "sit" when they heard the word "sea", and only one student picked up the word "neat" when broadcasted the word "nit".

Table 4. Minimal Paris of vowels /e/-/ $/(\mathrm{N}=17)$

\begin{tabular}{lll}
\hline Words & Vowels & $/ \varepsilon /$ \\
\hline fate /fet/ & 15 & 2 \\
letter /letz/ & 8 & 9 \\
late /let/ & 11 & 6 \\
bait /bet/ & 14 & 3 \\
\hline
\end{tabular}

According to Table 4, only two participants chose "fed" when they heard "fate". A half of students feel confused with the vowels /e/-/E/ pair between the words "letter" and "later". Six of them chose the word "let" when they heard "late". Only three of the students picked up the word "bet" when they heard "bait". 
Table 5. Minimal Paris of vowels /e/-/æ/ $(\mathrm{N}=17)$

\begin{tabular}{lcc}
\hline Words & Vowels & / $/ \mathfrak{e} /$ \\
\hline fat $/ \mathrm{fæt} /$ & 5 & 12 \\
lab $/ \mathrm{læb} /$ & 0 & 17 \\
\hline
\end{tabular}

Table 5 indicated that most of the students could recognize /e/-/æ/ pair easily. There were only five participants chose the word "fate" when they heard "fat". None of them chose late when they heard "lab".

Table 6. Minimal Paris of vowels $/ \varepsilon /-/ æ /(N=17)$

\begin{tabular}{|c|c|c|}
\hline Words Vowels & $/ \varepsilon /$ & $/ \mathfrak{~ / ~}$ \\
\hline sad /sæd/ & 1 & 16 \\
\hline let /let/ & 13 & 4 \\
\hline letter /lعtə/ & 10 & 7 \\
\hline
\end{tabular}

As Table 6 shown, only one student chose the word "said" when they heard "sad" $(\mathrm{N}=16)$. Four of them picked up "lab" when they heard "let" $(\mathrm{N}=13)$. However, there were seven participants chose "latter" when they heard "letter" $(\mathrm{N}=10)$.

Table 7. The most confused English front vowels in perceiving $(\mathrm{N}=17)$

\begin{tabular}{|c|c|c|c|c|c|c|}
\hline & $/ \mathrm{i} /$ & $/ \mathrm{I} /$ & /e/ & $/ \varepsilon /$ & $/ \mathfrak{l} /$ & Total \\
\hline bat /bæt/ & & & & 8 & 9 & 17 \\
\hline bet /bct/ & 2 & 2 & 2 & 7 & 4 & 17 \\
\hline latter /lætə/ & & & 4 & 6 & 7 & 17 \\
\hline letter /letə/ & & & 4 & 7 & 6 & 17 \\
\hline
\end{tabular}

Table 7 clearly displayed that students would be confused easily when they heard "bat/bæt/", "bet /bet/", "latter $/$ lætə/" and "letter /letə/". In the word "bat", eight of participants chose vowel $/ \varepsilon /$. Each of two learners chose vowel $/ \mathrm{i} /, / \mathrm{I} /$ and $/ \mathrm{e} /$, and four students chose vowel /æ/ when they heard the word "bet". In addition, students would misunderstand the sound "latter" in the vowels /e/ $(\mathrm{N}=4)$ and $/ \varepsilon /(\mathrm{N}=7)$. They can't also make distinguish briefly among vowels /e/ $(\mathrm{N}=4), / \mathcal{E} /(\mathrm{N}=7)$ and /æ/ $(\mathrm{N}=6)$ when they heard the word "letter".

Research question 2: Among the five front vowels $/ \mathrm{i} /, / \mathrm{I} /, / \mathrm{e} /, / \varepsilon /, / \mathfrak{a} /$, which front vowels do college students perform the best or worst in speaking?

Table 8. Frequencies of English front vowels production $(\mathrm{N}=17)$

\begin{tabular}{lllllllllll}
\hline Vowels & $/ \mathrm{i} /$ & & $/ \mathrm{I} /$ & & $/ \mathrm{e} /$ & & $/ \varepsilon /$ & & $/ \mathfrak{\wp} /$ \\
\hline$f$ & $\mathrm{~N}$ & $\%$ & $\mathrm{~N}$ & $\%$ & $\mathrm{~N}$ & $\%$ & $\mathrm{~N}$ & $\%$ & $\mathrm{~N}$ & $\%$ \\
\hline 0 & 11 & 64.7 & & & 8 & 47.1 & & & 10 & 58.8 \\
1 & 1 & 5.9 & & & 4 & 23.5 & & & 2 & 11.8 \\
2 & & & & & 2 & 11.8 & & & 1 & 5.9 \\
3 & & & & & & & 4 & 23.5 & & \\
4 & 3 & 17.6 & 2 & 11.8 & 1 & 5.9 & 2 & 11.8 & 1 & 5.9 \\
5 & 2 & 11.8 & 15 & 88.2 & 2 & 11.8 & 11 & 64.7 & 3 & 17.6 \\
Total & 17 & 100 & 17 & 100 & 17 & 100 & 17 & 100 & 17 & 100 \\
\hline
\end{tabular}

Table 8 showed that students produced the best in $/ \mathrm{I} /(\mathrm{N}=17,4 \leqq f=5)$, the next is $/ \varepsilon /(\mathrm{N}=13,4 \leqq f=5)$. Few students pronounced well in the vowel $/ \mathrm{i} /(\mathrm{N}=5,4 \leqq f=5)$ and /e/ $(\mathrm{N}=3,4 \leqq f=5)$ which should be pronounced longer. Only few students pronounced well the vowel $/ \mathfrak{x} /(\mathrm{N}=4,4 \leqq f=5)$. 
Research question 3: Is there a correlation between English perception and production of these English vowels?

Table 9. Correlation between production and perception of English front vowels

\begin{tabular}{ll}
\hline & Production of English front vowels \\
\hline Perception of English front vowels & $.63^{* *}$ \\
\hline
\end{tabular}

${ }^{* *} p<.01$, two-tailed.

As shown in Table 9, there was a positive and significant relationship between production and perception of English front vowels. While learners pronounce well in English, they would have good performance in English listening. In other words, they can't perceive well when they hold low proficiency in pronouncing.

The results of the present study are summarized as follows:

1) Participants perceived the best in /i/-/I/ pair and /e/-/æ/ pair but the worst in /e/-/E/ pair, /E/-/æa/ pair and among $/ \mathrm{e} /-/ \varepsilon /-/ \mathfrak{m} /$ pair.

2) Participants produced the best in the vowels of /I/ and /E/ but the worst in the vowels of /i/, /e/ and /æ/.

3) There was a strong and positive correlation between production and perception of English vowels by college students.

\section{Conclusion}

The main purpose of this study was to probe the perception and production of five English front vowels by college students. Moreover, the correlation between English perception and production of English front vowels was explored. A total of 17 college students who studied in southern Taiwan were recruited in this survey. The participants were required to do the perception tests and production tests of English front vowels. Discussion on significant findings is presented firstly. Pedagogical implications and suggestions for future research are then provided to conclude this study.

\subsection{Perception of English Front Vowels}

Consistent with previous study (Lin, 2013), students perceived /i///I/ pair better than $/ \varepsilon /-/ \mathfrak{a} /$ pair. Zhou, Chen and Dai (2011) also probed that students perceived well in /i/, /I/while they perceived worst in /æ/. To students, /i/ and /I/ are apparent and easy to separate the longer sound or the shorter sound. However, students would mix up easily in $/ \mathcal{E} /-/ \mathrm{e} /-/ \mathfrak{a} /$ pair which was consonant with previous study (Ho, 2010). EFL teachers should strengthen the training for students on $/ \varepsilon /-/ e /-/ \mathfrak{e} /$ pair and make them clearly understand the difference and the tongue position among /E/-/e/-/æ/ pair.

\subsection{Production of English Front Vowels}

Cheng (2004) indicated that Taiwanese adult learners have problems in pronouncing /i/ and /e/ than $/ \mathrm{I} /$ and $/ \varepsilon /$. It is consistent with the current study. The sound of $/ \mathrm{i} /$ and /e/ should be pronounced longer, but students are not familiar with them because of their L1. Students also produced worst in /æ/ which is not exist in their L1 (Chinese). By the way, students have no idea in the height of tongue position. Lin (1994) also supported that Chinese learners misunderstand /i/-/I/ pair because there is no difference in Chinese. The results were also consistent with previous studies (Chen, Chang, Yang, \& Chou, 2006)

\subsection{Correlation between Perception and Production of English Front Vowels}

Cho and Jeong (2013) argued that there was no significant correlation between perception and production of English front vowels. However, the results of current study were in opposition to it. While learners have good performance in pronouncing, they tend to be good at listening in English, the results of this study were consistent with previous studies (Lin, 2013; Mokari, Famian, \& Ghafoori, 2013).

\subsection{Pedagogical Implications}

Based on the results found in the current research, three pedagogical suggestions for EFL teachers are addressed. First, English teachers should pay more attention to instruct students how to distinguish vowel pairs, especially for the $/ \mathrm{e} /-/ \varepsilon /$ pair, $/ \varepsilon /-/ æ /$ pair and among /e/-/E/-/æ/ pair which confused students easily in terms of perception. The results of this study also indicated that students have difficulties in producing /i/, /e/ and /æ/ that English teachers should teach students how to separate in the vowel pairs and the height of tongue position when they are 
practicing English front vowels in terms of perception and production. Second, this study found that there was a strong and positive correlation between English perception and production that English teachers should emphasize both to instruct students. Third, many people think that the younger learners learn foreign language can get better effect. However, Chen, Chang, Yang, and Chou (2006) stated that there is no difference between early and late EFL learners. EFL teachers should give learners correct English instruction in producing and perceiving and make them to be confident in producing and perceiving English.

\subsection{Limitations and Future Studies}

Based on the findings of the study, there are some suggestions for future research. Firstly, the findings was only limited to the college students in southern Taiwan, future studies may expand the coverage of surveying areas in northern and southern Taiwan. Secondly, the subjects of English major and non-English major were not balanced. To get a more general picture of the learners' proficiency of producing and perceiving English front vowels, an equivalent number of students from English major and non-English major may be recruited.

\section{References}

Barboza, C. L. F. (2007). Production of English vowels by Brazilian EFL teachers in western Rio Grande do Norte. Proceedings of the Fifth International Symposium on the Acquisition of Second Language Speech, 28-37.

Chen, L. M., Chang, Y. H., Yang, C. S., \& Chou, Y. H. (2006). Production and perception errors in English vowels. Annual Meeting and $19^{\text {th }}$ Symposium of Acoustical Society of the Republic of China, 1-6.

Cheng, M. C. (2004). A study on production of English vowels by Taiwanese adult learners: An acoustic perspective. Journal of National Kaohsiung University of Applied Sciences, 33, 131-144.

Cho, M. H., \& Jeong, S. (2013). Perception and production of English vowels by Korean learners: A case study. Studies in phonetics, phonology and morphology, 19(1), 155-177.

Ho, Y. K. (2010). Technical university freshmen's problems in English segmental pronunciation-a case study of English front vowel perception. Minghsin Journal, 36(2), 33-44.

Lin, M. (1994). English learning: An analysis of Chinese students'problems in pronunciation. Retrieved from http://www.eric.ed.gov/contentdelivery/servlet/ERICServlet?accno=ED411668

Lin, C. Y. (2013). Perception and production of English front vowels by Taiwanese EFL learners. Theory and Practice in Language Studies, 3(11), 1952-1958. http://dx.doi.org/10.4304/tpls.3.11.1952-1958

Lin, Y. L., \& Chen, L. M. (2005). English vowel perception in Mandarin-Speaking Children. Selected papers from the fourteenth International Symposium in English Teaching, 2, 194-201.

Mokari, P. G., Famian, A. R., \& Ghafoori, N. (2013). An acoustic of production and perception of English vowels by Azeri English learners. Journal of Basic and Applied Scientific Research, 3(7), 84-91.

Tseng, W. C. (2011). A study of Taiwanese high school students' production and perception performance in English non-high front vowels. Retrieved from http://ndltd.ncl.edu.tw/cgi-bin/gs32/gsweb.cgi/login?o= dnclcdr\&s $=\mathrm{id}=\% 22099$ STUT8741022\%22.\&searchmode=basic

Wan, X. C. (1997). The acquisition of English vowels by Mandarin ESL learners: A study of production and perception. Retrieved from http://www.nlc-bnc.ca/obj/s4/f2/dsk2/ftp04/mq24263.pdf

Zhou, W., Chen, H., \& Dai, L. (2011). Perception of English monophthongs by native speakers of Mandarin. Regular Session, 17-21, 2320-2323.

\section{Copyrights}

Copyright for this article is retained by the author(s), with first publication rights granted to the journal.

This is an open-access article distributed under the terms and conditions of the Creative Commons Attribution license (http://creativecommons.org/licenses/by/3.0/). 